\title{
Process for reinforcing SLS parts by epoxy resin
}

\author{
Mario D. Monzon, Rubén Paz and Fernando Ortega \\ Department of Mechanical Engineering, University of Las Palmas de Gran Canaria, Las \\ Palmas de Gran Canaria, Spain \\ Jose A. Chapela and Claudio Conde \\ Rapid Prototyping Laboratory, Centro Tecnológico de automoción de Galicia (CTAG), \\ Porriño, Pontevedra, Spain
}

\begin{abstract}
Purpose - The purpose of this paper is to report on the use of a combination of selective laser sintering (SLS) and vacuum casting to create plastic composites made by additive manufacturing.
\end{abstract}

Design/methodology/approach - The research has been carried out by approaching a new concept of the final part consistent in a plastic component, where the main body is made by SLS and the internal long fibres for reinforcing are made by vacuum casting of high-resistance epoxy resin. The part is designed for optimal number and distribution of the internal fibres taking into account the target relative stiffness $(\mathrm{N} / \mathrm{mm} * \mathrm{~kg})$. The methodology is applied to a pedal clutch of a car which has been tested in an equipment for fatigue and durability, being compared to the correspondent design for injection moulding.

Findings - Research has proven that the approach introduces relevant improvement in mechanical properties of the base resin consistent in PA 3200GF (EOS), reinforced by internal long fibres of resin VG SP5. Experiments showed significant increase of stiffness in the pedal clutch made under this procedure, where the stiffness was 77 per cent higher than the conventional SLS part and only 11.7 per cent lower than the one made by injection moulding of PA 66 with 50 per cent fibreglass.

Originality/value - The developed method introduces an alternative procedure for increasing the mechanical properties of plastic parts developed in SLS. Optimal orientation and distribution of long fibres clearly achieves better mechanical properties at low cost.

Keywords: Composites, Selective laser sintering

\section{INTRODUCTION}

Nowadays Additive Manufacturing (AM) technologies are being introduced in the mechanical industry as procedure to manufacture final parts (in the past few years this concept used to know as Rapid Manufacturing or Rapid Prototyping) (Gibson et al., 2009; Esteve et al., 2012). However some challenges have to be carried out such as availability of technical advanced materials and variability of them, reliability and reproducibility of AM processes as well as lower cost than the conventional procedures (machining, casting, welding). Issues as standardization of AM is also a key point for introducing these technologies in those fields where the standard is necessary 
(aeronautic, automotive, medical, etc.), in this sense the activities of ASTM (F42 committee) and ISO (TC 261 committee) are going in the correct direction for solving this gap and in the next couple of years the industry will be provided of several standard rules including terminology, procedures, testing and digital data exchange.

However, as seen later, there are still some limitations in some AM technologies for enabling high quality parts suitable to replace parts made by conventional manufacturing processes. This paper is focused on Selective Laser Sintering (SLS) for plastics (Kumar, 2003), where despite the high evolution of this technology in the last decade, there are still some difficulties in being an acceptable alternative, to traditional injection moulding, in some applications where the mechanical requirements of the final part are significantly high. This is the case of those components injected with glass fiber such as polyamide (PA) with $50 \%$ glass fiber (GF). The polyamide with glass fiber (Jain et al., 2006), typically used in SLS cannot replace this injected material because the results do not reach the minimum necessary requirement. Some authors (Shi et al., 2007) have approached infiltration of epoxy resin as post-process in SLS parts of polycarbonate, improving the mechanical properties. Stevinson et al. (2008) evaluated mechanisms for silicon overfilling for composite silicon/silicon carbide (SiC) objects generated using post-process infiltration of selective laser sintered (SLS) SiC performs, these composites were found to be thermally stable with good material bonding.

However plastic composites need to be more upgraded in AM because composites have become in essential components of automotive sector or aeronautical. Although some AM technologies have implemented the option of multi-material (for example PolyJet ${ }^{\mathrm{TM}}$ ) and in some way could be considered as a plastic composite, the limitations of the available materials make them to be unsuitable to replace conventional injected parts with glass fiber.

The aim of this research work is to extend the application of SLS plastic parts to high capability products, such as needed in the automotive industry, usually made by injection moulding. An alternative procedure is proposed, being SLS the technology for making plastic parts reinforced by multiple and multidirectional internal long fibers formed by high resistance material (in this work epoxy resin).Therefore the global approach is to have the option to combine design for lightening with design for reinforcing by long fibers in selected locations of the part. The paper mainly focuses on reinforcing.

\section{PRELIMINARY WORK}

In order to compare the different behaviour between a part made by injection moulding and another one by SLS, several preliminary tests were carried out. The case study is based on a clutch pedal of a car, design provided by the technological centre of automotive in Galicia, CTAG (Spain). The material usually injected is polyamide PA 66 with $50 \%$ glass fiber. Several replica samples with identical geometry were sintered by SLS using polyamide PA 3200 GF (EOS) (Figure 1). At this point is important to clarify that the 3D design for the SLS clutch pedal is not so optimal for AM because this design was developed for injection moulding where the restrictions and specifications were taken into account (for example the hollow cells for enabling the extraction during the injection cycle). 


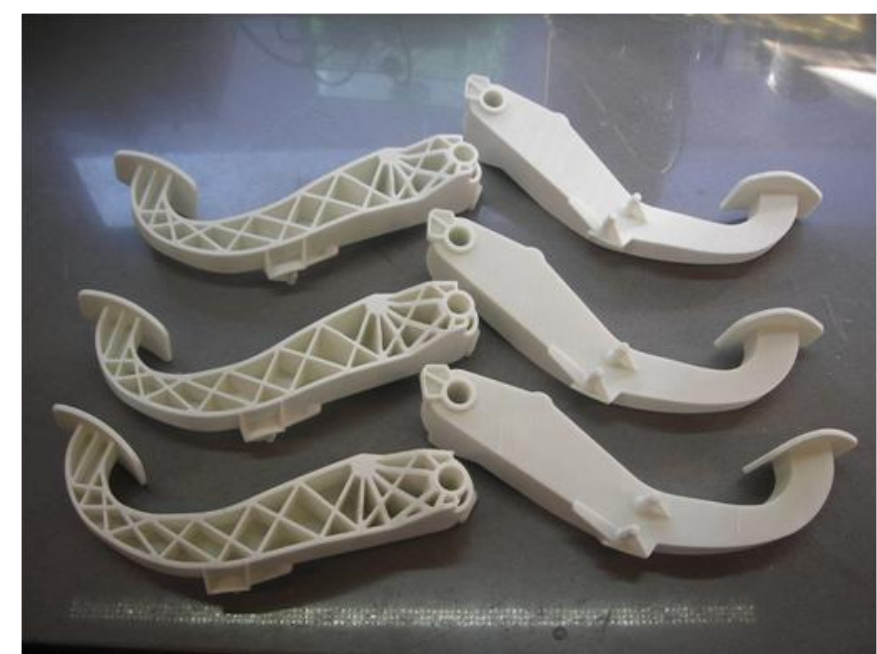

Figure 1. SLS clutch pedal in preliminary work

The SLS models were manufactured in the equipment EOSint P380, laser solid state

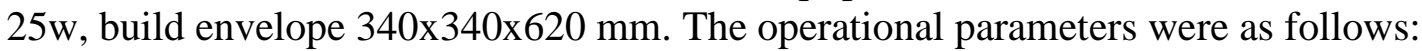

- Layer thickness: $0.15 \mathrm{~mm}$

- Laser power: $43 \mathrm{~W}$

- Hatching mode: alternative X-Y

- Hatching speed: $3000 \mathrm{~mm} / \mathrm{s}$

- Beam offset hatching: $0.63 \mathrm{~mm}$

- Boundary power: $12 \mathrm{~W}$

- Boundary beam offset: $0.33 \mathrm{~mm}$

- Exposure mode: sorted

- Temperature: $175-177^{\circ} \mathrm{C}$

- Recyclable material: $50 \%$

Two different orientations of the models on the platform were carried out. First position (vertical direction), where the layers were oriented more or less in parallel to the plane formed by the pushing area of the pedal. The second position (horizontal direction) was with the layers oriented along the main axis of the pedal (the same position on the building platform as the one shown in Figure 1). The idea is to check the different result in terms of mechanical properties. In fact due to the strong influence of the operational parameters on the mechanical properties a specific characterization of PA 3200GF was done by testing as seen later.

\subsection{Experimental work}

The equipment for determining the stiffness of the clutch pedal is very common for testing brakes and clutch in the automotive industry (Figure 2). The equipment used in this research is basically composed by a support structure where the pedal is assembled and can be fixed in several positions depending on the category of test to do (stiffness, maximum strength, fracture, clearance, etc). To test the stiffness of clutch pedal the pedal was fixed under a position equivalent to $2 / 3$ of the maximum run. The pushing 
force is measured by a load cell (Figure 2) and the displacement by two position sensors (one measuring in the $\mathrm{XZ}$ plane and the second one in the $\mathrm{Y}$ axis).

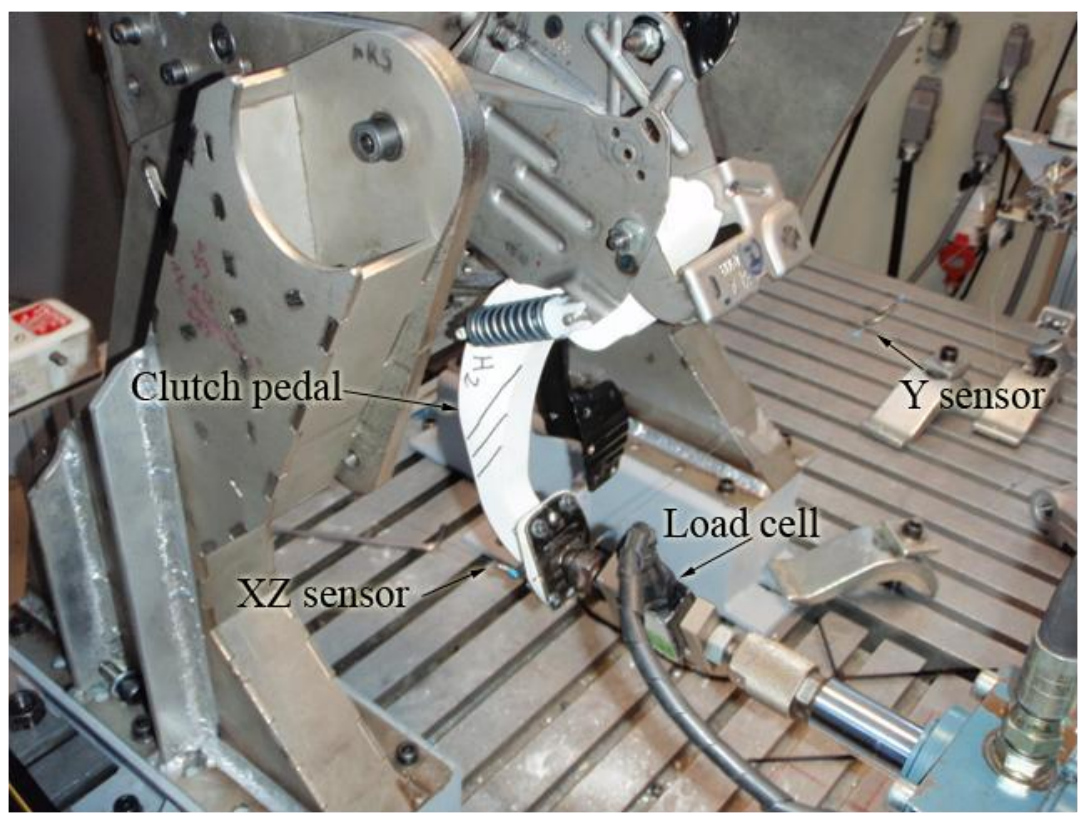

Figure 2. Equipment used for testing the clutch pedal

The pushing cylinder has to be oriented in a perpendicular line to the axis $\mathrm{O}-\mathrm{M}$, being $\mathrm{O}$ the rotation point and $\mathrm{M}$ the point where the force $\mathrm{F}_{\mathrm{xz}}$ is pushing on the pedal (Figure 3). By mean of a data logger force and displacement are recorded under real time. 


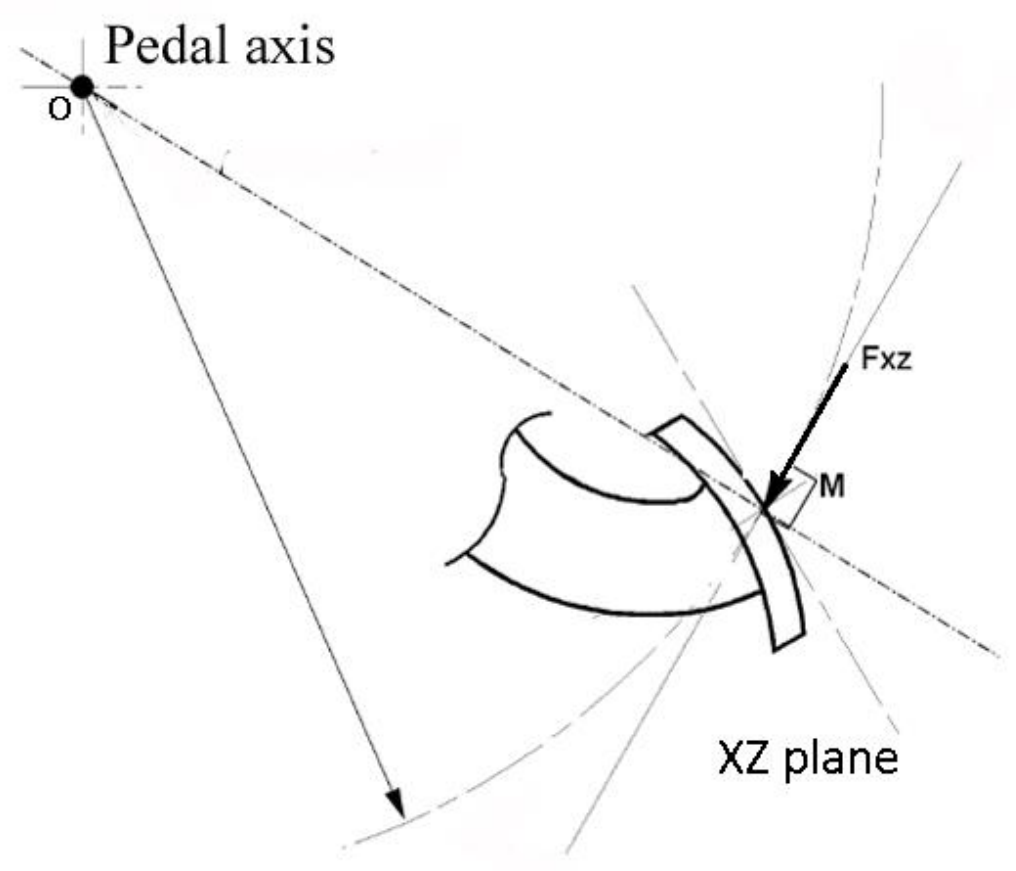

Figure 3. Orientation of the force $\mathrm{F}_{\mathrm{xz}}$ perpendicular to $\mathrm{O}-\mathrm{M}$

\subsection{Results of preliminary work}

The test criterion was to measure the displacement once the force reaches a value of 150 $\mathrm{N}$ (common value in this kind of test in the automotive industry). Only displacement in plane $\mathrm{XZ}$ was measured. The table 1 shows a summary of the results for each type of pedal: injected with PA66 $+50 \%$ glass fiber, SLS PA 3200GF with layers in vertical direction and SLS PA 3200GF with layers in horizontal direction.

Properties of PA66+50\%GF and PA3522GF are different according to their data sheet (12500MPa and $3200 \mathrm{MPa}$ of tensile modulus, respectively). This difference is mainly due to the length of the GF. In the case of PA3200GF the mean particle size is $57 \mu \mathrm{m}$, while GF in PA66+50\% GF is up to $1 \mathrm{~mm}$ length. Moreover the percentage of GF in PA3200GF is unknown.

\begin{tabular}{|l|c|c|c|}
\hline & PA66+50\% GF & $\begin{array}{c}\text { SLS PA 3200GF } \\
\text { Vertical }\end{array}$ & $\begin{array}{c}\text { SLS PA 3200GF } \\
\text { Horizontal }\end{array}$ \\
\hline Displacement XZ $(\mathrm{mm})$ & 2.15 & 15.7 & 11.04 \\
\hline Stiffness $(\mathrm{N} / \mathrm{mm})$ & 698.8 & 95.5 & 135.9 \\
\hline
\end{tabular}

Table 1. Results of tests comparing injection moulding to SLS

As expected the behaviour of the polyamide with fiber glass used in SLS is clearly worse than the injected part, being even the best result of SLS about $80 \%$ worse in stiffness. Some references show similar conclusion such as L. Cevolini et al. (2008) where a SLS dashboard of a motorbike was made, using as SLS material Windform XT, and compared to injected dashboard made with PA6-BG35, having better mechanical properties the injected part. 
Also is observed the best result for the SLS pedals made with layers in vertical direction which is also expected due to the laminar structure more suitable for applying the force as $\mathrm{F}_{\mathrm{xz}}$ is. Similar conclusions related to anisotropy in the growth direction (z axis) are observed in the research carried out by Berti et al. (2010) applied to PA-Al2O3 composite for selective laser sintering (SLS) and in the work carried out by E. Bassoli et al. (2012) in the case of metal or ceramic filler.

In conclusion either the design or the material of SLS part has to be changed if this technology is wanted to be used for this kind of clutch pedal.

The alternative proposal is commented in the following sections.

\section{THE APPROACH: SLS MULTI-FIBER COMPOSITE}

In this stage of the research a new pedal was selected from the models tested by CTAG. This new model corresponds to a more modern design. The O-M length of the pedal (according to Figure 3 ) is $188.5 \mathrm{~mm}$. In Figure 4 is shown the design where the original ribs of the injected part can be observed. The steps followed in this stage were:

- To redesign the pedal by Finite Element Method (FEM) and selection of the best option for placing the internal long fibers.

- To manufacture the pedal under SLS with hollow rounded channels according to the previous design.

- To fill the channels with epoxy resin by vacuum.

- To test the pedals in the equipment commented in 2.1

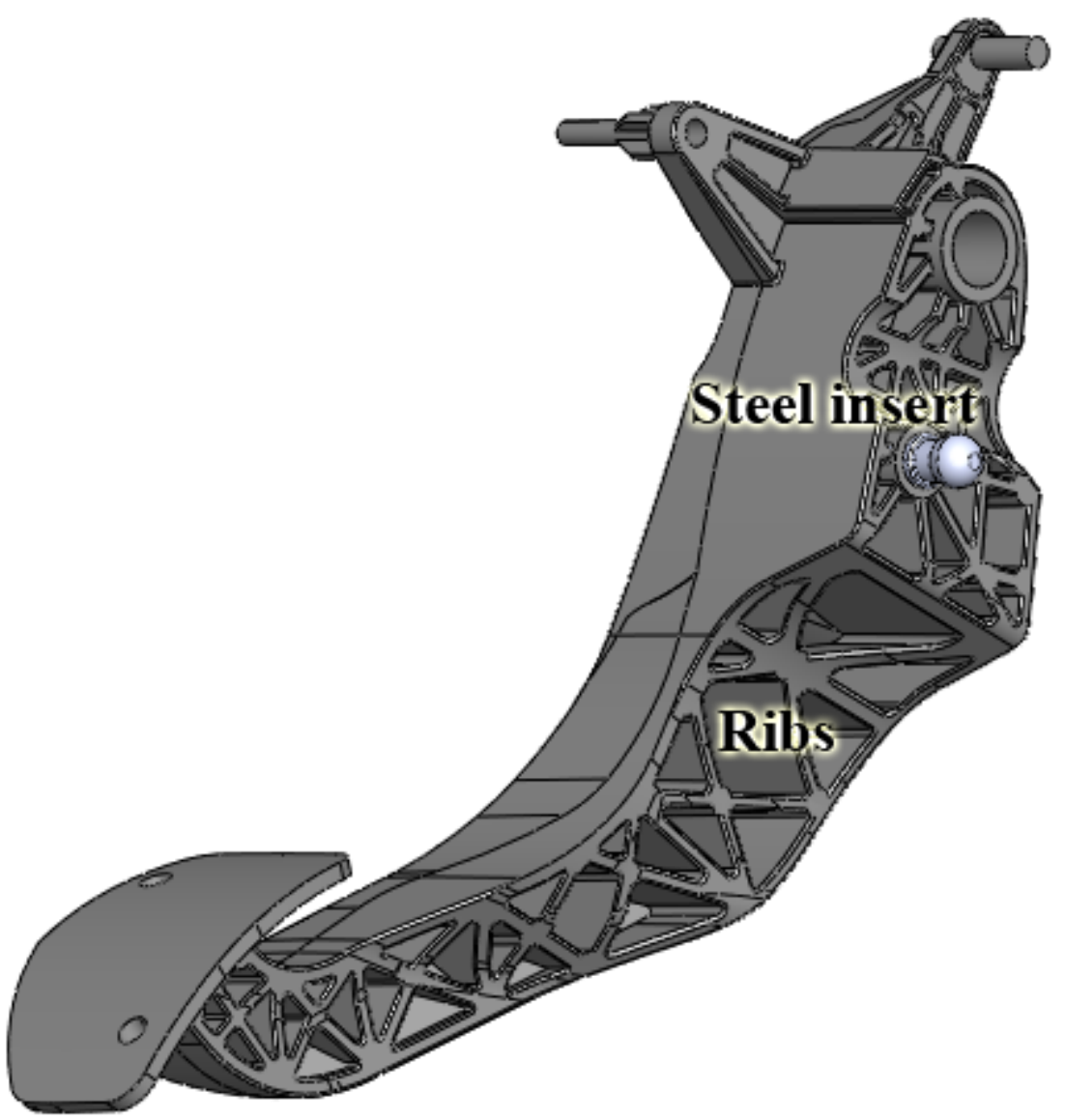

Figure 4. Geometry of clutch pedal tested in this stage 


\subsection{Design process of SLS multi-fiber composite}

First of all the reinforced design was kept similar to the original one in the external shape, where the ribs were removed, having an external smooth surface. It is important to note that the global modification of this design could be more radical and oriented to AM but this research had some limitations in the equipment for testing, where the available tooling was adapted to the original design of the injected part. In consequence the redesign was mainly in the internal body of the part.

The considered materials were as follows:

- SLS material of main body: PA 3200GF (EOS), density $1.22 \mathrm{~g} / \mathrm{cm}^{3}$

- Resin of internal fibers: VG SP5 (MCP), density $2.7 \mathrm{~g} / \mathrm{cm}^{3}$

Before introducing the mechanical properties in the FEM software (SolidWorks), standard samples of the SLS material were sintered using the same parameters that the operational parameters in pedals. The technical specifications of this material, provided by the supplier, do not represent all the possibilities because of the variability of results when the operational parameters and direction of fabrication, rate of recycled material are modified (Monzón et al., 2009). The tensile test was carried out under the standard ISO 527-1 (at that time no standard for AM was still available, today there is available standard UNE116005=2012 specific for AM). The tensile test was done in a machine for dynamic testing, Microtest, $5000 \mathrm{kN}$ maximum load. Tensile strength, tensile modulus and elongation were measured at $10 \mathrm{~mm} / \mathrm{min}$ testing speed and are shown in table 2.The samples were sintered by placing them in a horizontal position on the building platform. The average tensile modulus obtained in these tests was $990.66 \mathrm{MPa}$. Also standard samples for flexural testing were manufactured together with the tensile samples and tested under the standard ISO 178:2003. The average flexural modulus obtained was $1713 \mathrm{MPa}$, higher than the tensile modulus. However the most critical value $(990.66 \mathrm{MPa})$ was defined as elastic modulus in FEM simulations in order to implement a certain safety factor.

\begin{tabular}{|l|c|c|c|c|}
\hline & $\begin{array}{c}\text { Ultimate stress } \\
\mathrm{MPa}\end{array}$ & Ultimate strain & $\begin{array}{c}\text { Tensile } \\
\text { modulus } \\
\mathrm{MPa}\end{array}$ & $\begin{array}{c}\text { Proportional } \\
\text { limit stress } \\
\mathrm{MPa}\end{array}$ \\
\hline PA 3200GF & 28.94 & 0.0618 & 990.66 & 20.53 \\
\hline
\end{tabular}

Table 2. Results of tensile test of PA 3200GF under SLS parameters of this research

The E modulus of the resin VG SP5 (MCP) is $9800 \mathrm{MPa}$. Nevertheless this value is expected to be lower in this research because the followed thermal treatment was not exactly the recommended for this resin (this resin is used for making high temperature resistance epoxy mould under vacuum casting). In fact in the market better resins are available for the purpose of this approach, being expected better results. However it was selected due to the good behaviour of this resin under vacuum casting. The $\mathrm{E}$ modulus employed in the FEM simulations was $6000 \mathrm{MPa}$ (main value obtained from some sample tests without thermal treatment). 
Once the materials were characterized, different configurations with internal long fibers were simulated by FEM in an iterative process, introducing long fibers in those areas with high stress (Figure 5) to allocate the best material in these zones (Fiebig and Axmann, 2013). The design of the fibers was defined by circular section channels to facilitate the flow of the liquid resin during the casting process. In addition, all the channels were defined as thru hollows to guarantee the gas evacuation during the vacuum application. Boundary conditions were defined in the FEM model according to the real test. A bond contact between resin-PA3200GF and also between PA3200GFinsert was assumed. The radial displacement on the ball-and-socket joint of the steel insert (Figure 4) was constrained. Similarly, the radial displacement on the cylindrical face of the pedal (in the rotation axis) was also restricted. On the other hand, the normal displacements on the lateral faces of the pedal axis were constrained. Finally, the $150 \mathrm{~N}$ load was applied according to Figure 3.

The measured value in the simulations was the resultant displacement vector in the $\mathrm{M}$ point commented before (XZ and Y components combined). The aim was to evaluate the relation between stiffness and weight ("stiffness/weight" or "specific stiffness") and then select the design with the best ratio.

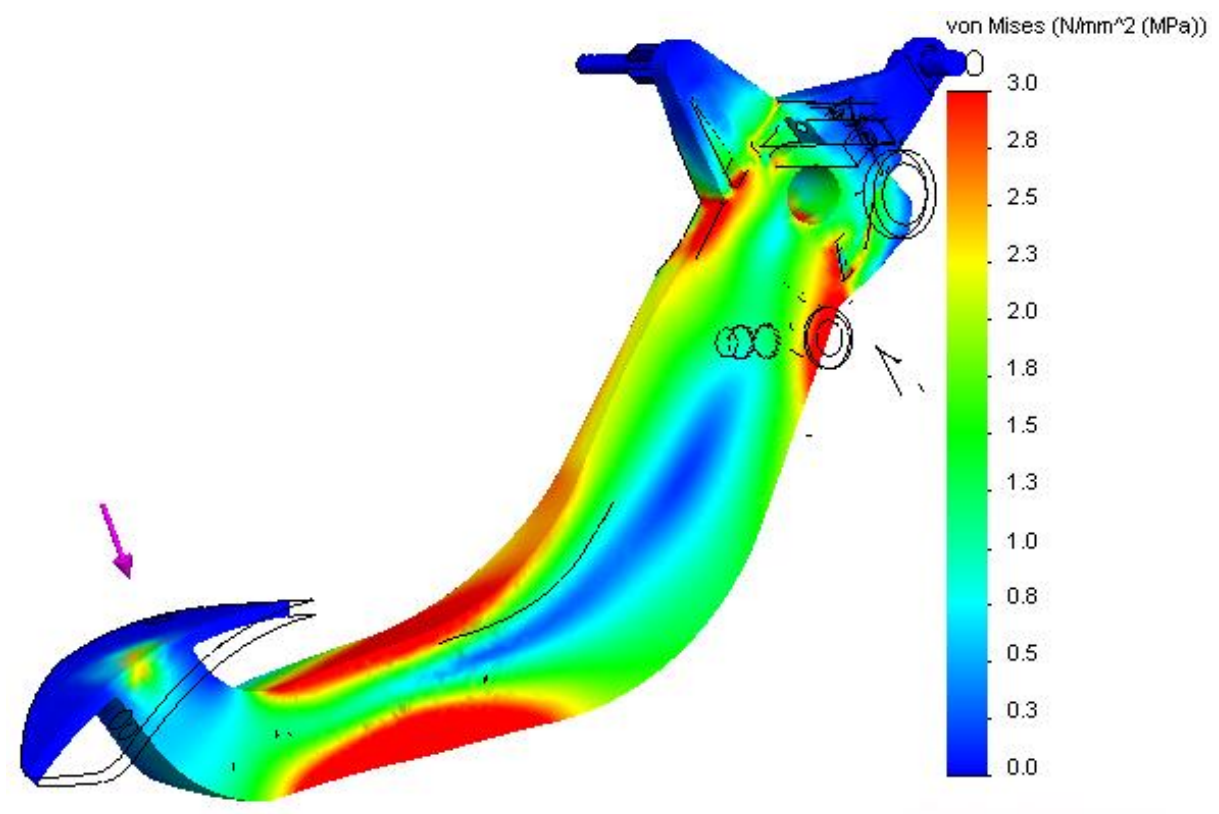

Figure 5. High stressed areas of the solid clutch pedal

Once known the more stressed zones, the first step was to define a feeding area to infiltrate the resin. It was defined in an accessible area (to facilitate the allocation of the feeding pipe) and also in a stressed zone in order to place resin in a stressed region.

After that, a first design (option 1) was defined with only one internal long fiber along the clutch pedal. Then, 3 long fibers were defined (option 2), branched from the feeding channel at the insert level in order to keep only one feeding zone. Two of them were placed in the upper zone, and the third one in the lower zone (most stressed regions) (Bruggi and Taliercio, 2013). Subsequently, a configuration with 5 long fibers was defined (4 in the upper zone and 1 in the lower, option 3). The next configuration was implemented adding a new fiber in the lower zone, with a total of 6 long fibers (option 4). Then, a new design was simulated, introducing another fiber in the lower zone, but 
in this case finishing it at the middle of the pedal (option 5). Subsequently, a new fiber was added, placing it in the lower zone at the beginning and in the upper zone at the end (option 6). The stiffness/weight ratio of the different configurations was increasing as new fibers were being added in the most stressed sectors. However, this last configuration (option 6) didn't increase this value because part of the new added fiber passes through a non-stressed area when changes its location from the lower to the upper zone, which means more density and rigid material in a low stressed region. At this point it was observed that the most important stresses appeared in the zone between the pedal axis and the insert. Thus, the next configuration was defined from the 7 long fiber design (option 5), just adding a new short fiber near to the rotation axis (option 7). The stiffness/weight ratio increased significantly. For this reason, the next simulated design was defined adding 2 new short fibers between the pedal axis and the insert (option 8). After that, the most stressed zones were observed near to the insert. So, a new short fiber was defined in this zone, joining it to one of the upper long fibers (option 9). However, the stiffness/weight ratio didn't increase. Hence, option 8 was considered the best design according to the specific stiffness value

The 9 simulated configurations are summarized as follows:

- Option 1: One internal long fiber

- Option 2: Three internal long fibers

- Option 3: Five internal long fibers

- Option 4: Six internal long fibers

- Option 5: Seven internal long fibers (Figure 6)

- Option 6: Eight internal long fibers (Figure 6)

- Option 7: Seven internal long fibers and one short fiber near to the rotation axis (Figure 6)

- Option 8: Seven internal long fibers, one short fiber near to the rotation axis and two short fibers between the rotation axis and the ball-and-socket joint insert (Figure 6)

- Option 9: Seven internal long fibers, one short fiber near to the rotation axis, two short fibers between the rotation axis and the ball-and-socket joint insert and one fiber under the ball-and-socket joint insert 


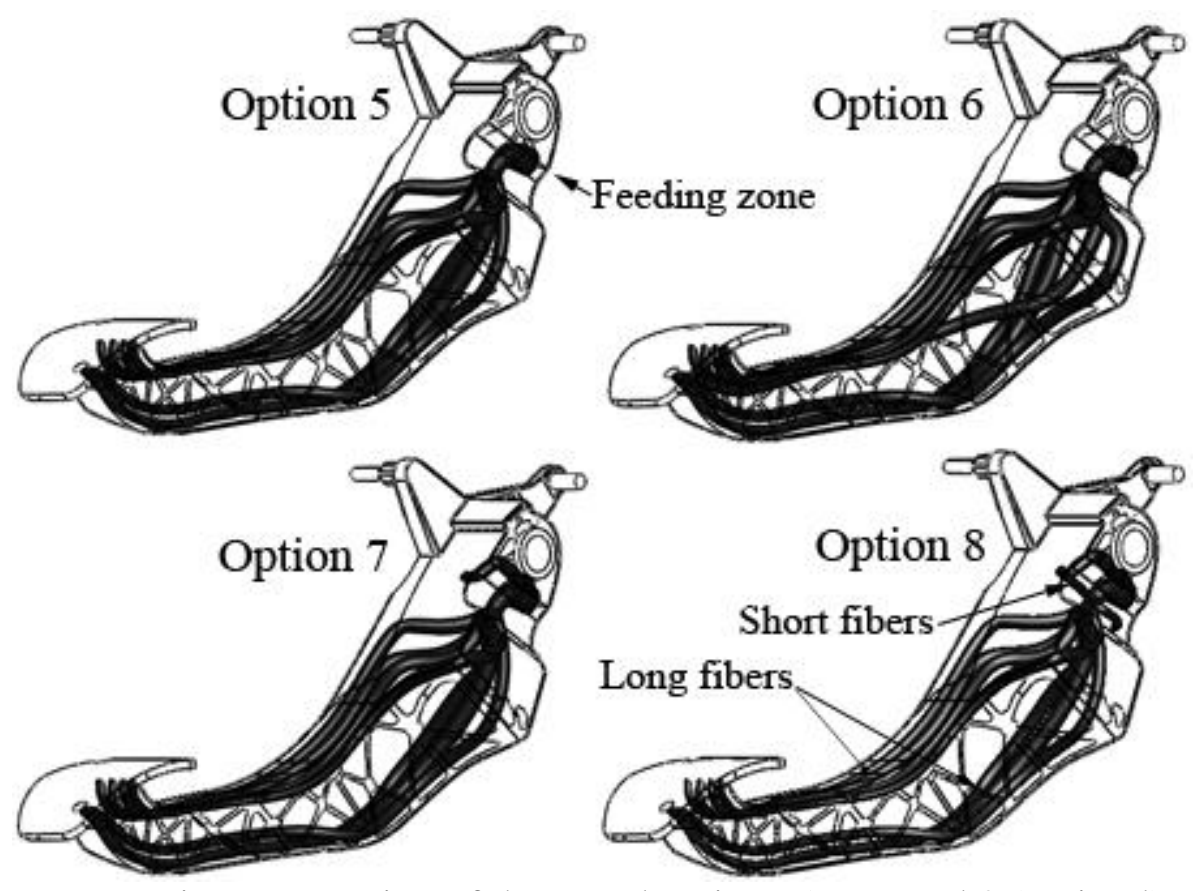

Figure 6. Design of the tested options 5, 6, 7 and 8 (optimal).

The diameter of the fiber in the feeding zone was $11 \mathrm{~mm}$ in all the configurations simulated. This diameter was reduced progressively along the pedal until a minimum of $4 \mathrm{~mm}$ diameter depending on the configuration. For example in options from 4 to 9 , the diameter of the channel was reduced progressively from $11 \mathrm{~mm}$ (feeding section) to $7 \mathrm{~mm}$ in the section where the fiber is divided into several fibers. These fibers were also reduced progressively along the pedal until $4 \mathrm{~mm}$ in the extreme, except for the shortest long fiber introduced in options from 5 to 9 (lower zone) which had a constant diameter of $7 \mathrm{~mm}$. In the case of short fibers, all of them were defined with a constant diameter of $4 \mathrm{~mm}$, except the new short fiber added in the last configuration (option 9) which had an initial diameter of $7 \mathrm{~mm}$ and a final diameter of $4 \mathrm{~mm}$.

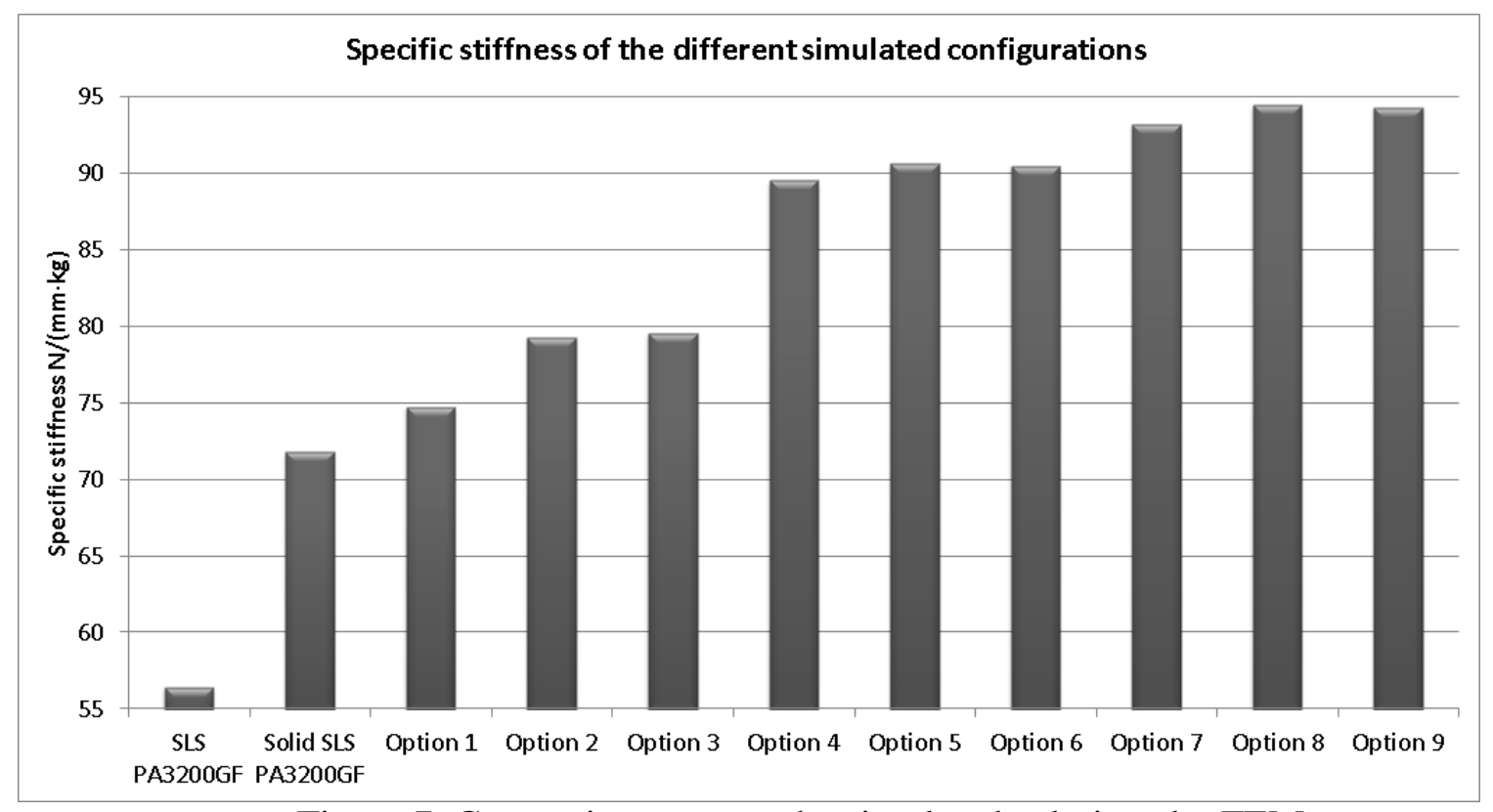

Figure 7. Comparison among the simulated solutions by FEM 
In Figure 7 is observed the significant difference between the specific stiffness of the option 8 and the one corresponding either to the original SLS design or the solid SLS design (geometry without internal fibers).

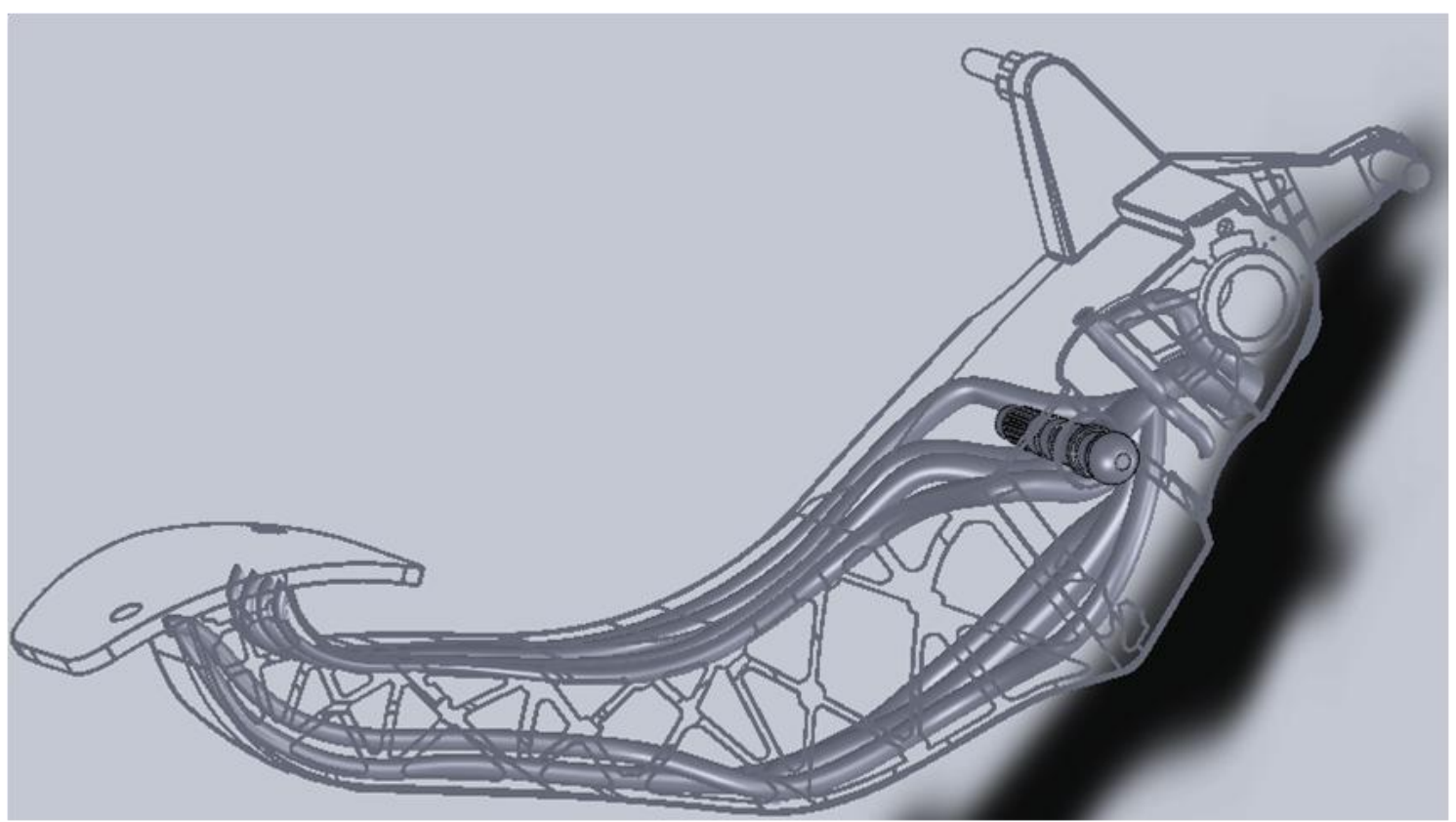

Figure 8. Best solution with 7 long fibers and 3 short fibers in the area of rotation axis

\subsection{Manufacturing process}

Once the solution number 8 was selected (Figure 8), the models of SLS were sintered under the same operational parameters than the used in the preliminary work (see section 2), having a SLS clutch pedal with similar geometry to the original injected part and a clutch pedal whit geometry according to solution number 8 (Figure 9).

The powder placed in the internal channels of the SLS hollow pedal was removed. The process of filling the channels with the epoxy resin VG SP5 was made in a similar way to the followed in the procedure for making epoxy moulds by vacuum casting. The only difference is that in this case the SLS part is in fact like a mould where the resin is introduced by vacuum. The SLS part is previously prepared by placing feeding pipes and funnels for the correct filling of all the internal fibers. The two components of the VG SP5 resin were heated at $40-50{ }^{\circ} \mathrm{C}$ and mixed in a plastic glass, being placed in an automatic equipment MCP OO1ST for vacuum casting where the liquid resin is introduced under vacuum into the SLS part. In order to avoid incomplete filling or bubbles the fluidity of the resin has to be controlled by the mentioned heating. The pot life of this resin (for 1000 grams) is between 160-180 minutes, in other words the time when the resin is starting to cure into the part. However, the previous heating of the components involves accelerating the chemical reaction and decreasing the pot life. In 24-48 hours the resin can be considered fully cured at room temperature. 
Once the resin is fully cured, a post tempering treatment is recommended (4 hours at $40^{\circ} \mathrm{C}$, then 2 hours each at $60 / 80 / 120 / 150^{\circ} \mathrm{C}$ ). However, taking into account the presence of PA3200GF and different coefficients of thermal expansion between the SLS material and the resin, this treatment wasn't applied (instead of this, the thermal treatment carried out was 4 hours at $40^{\circ} \mathrm{C}$ and 8 hours at $60^{\circ} \mathrm{C}$ ). This supposed a slightly loose of stiffness in the resin (from $9800 \mathrm{MPa}$ to approx. 6000MPa), but otherwise the PA3200GF will not suffer degradation and also the join between the resin and the SLS part will keep together practically without relative displacements (the higher the temperature, the higher the relative displacements). Finally, it is also known that the optimal mechanical properties of the resin are not achieved until one week later, reason why the mechanical test was carried out after this period of time.

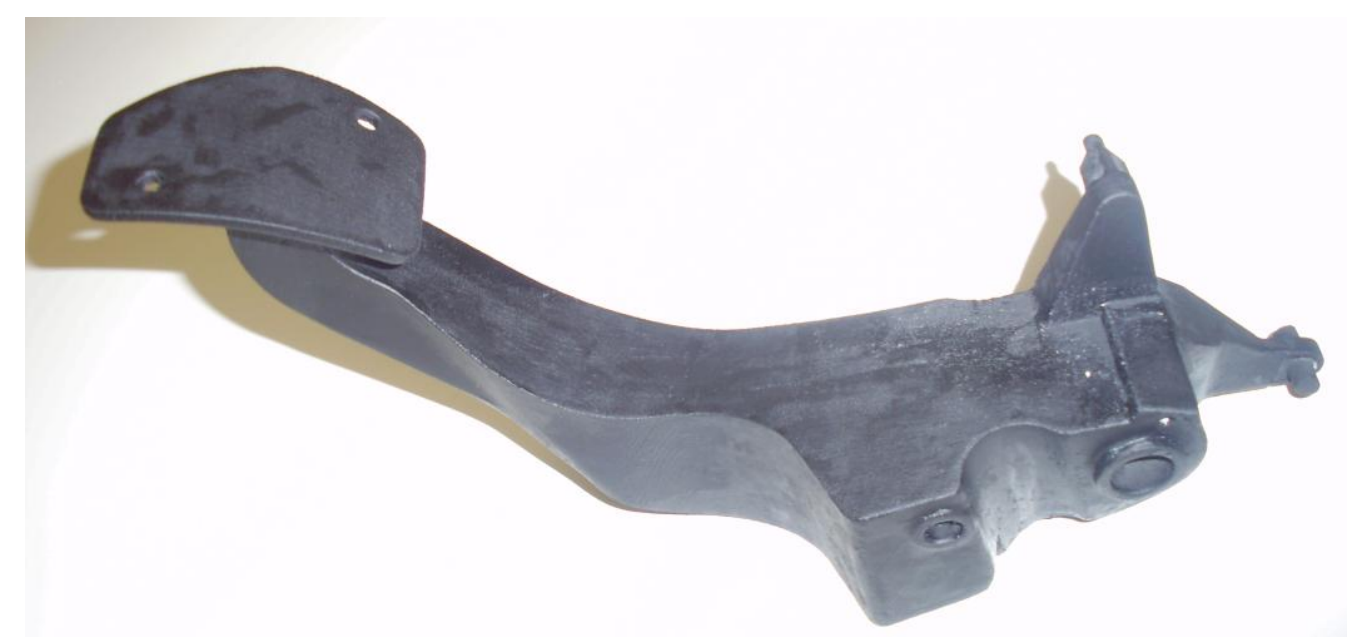

Figure 9. SLS reinforced clutch pedal corresponding to the solution 8

The disadvantage of this secondary process, as done in this research, is the manual operation of it, increasing the time and cost. However, for high productivity, an industrial implementation of this process could be viable if a continuous system for feeding SLS parts into the vacuum machine were possible being only necessary specific tooling for positioning the part into the equipment and an automatic cutting of the sprue. Even although the secondary process was done by manual method the total estimated cost per reinforced SLS part, including material, was 141 euros versus 125 Euros of the only SLS clutch pedal $(+12.8 \%)$. The cost versus the injected part is not competitive if cost is the main criteria, unless the number of parts to make is low. Nevertheless this last dilemma is equivalent to the existing one in injection moulding versus plastic SLS.

\subsection{Testing process}

The three categories of pedals were tested according to the procedure described in section 2.1: Injected clutch pedal PA66 + 50\% GF, SLS PA 3200GF and reinforced SLS PA 3200GF + VG SP5. The force applied on the surface of pedal (point M) was $150 \mathrm{~N}$ and the displacement in plane $\mathrm{XZ}$ and axis $\mathrm{Y}$ were measured.

In Figure 10 is seen the curves corresponding to the displacement and force of the reinforced SLS PA 3200GF + VG SP5 pedal either in XZ plane or Y axis. 


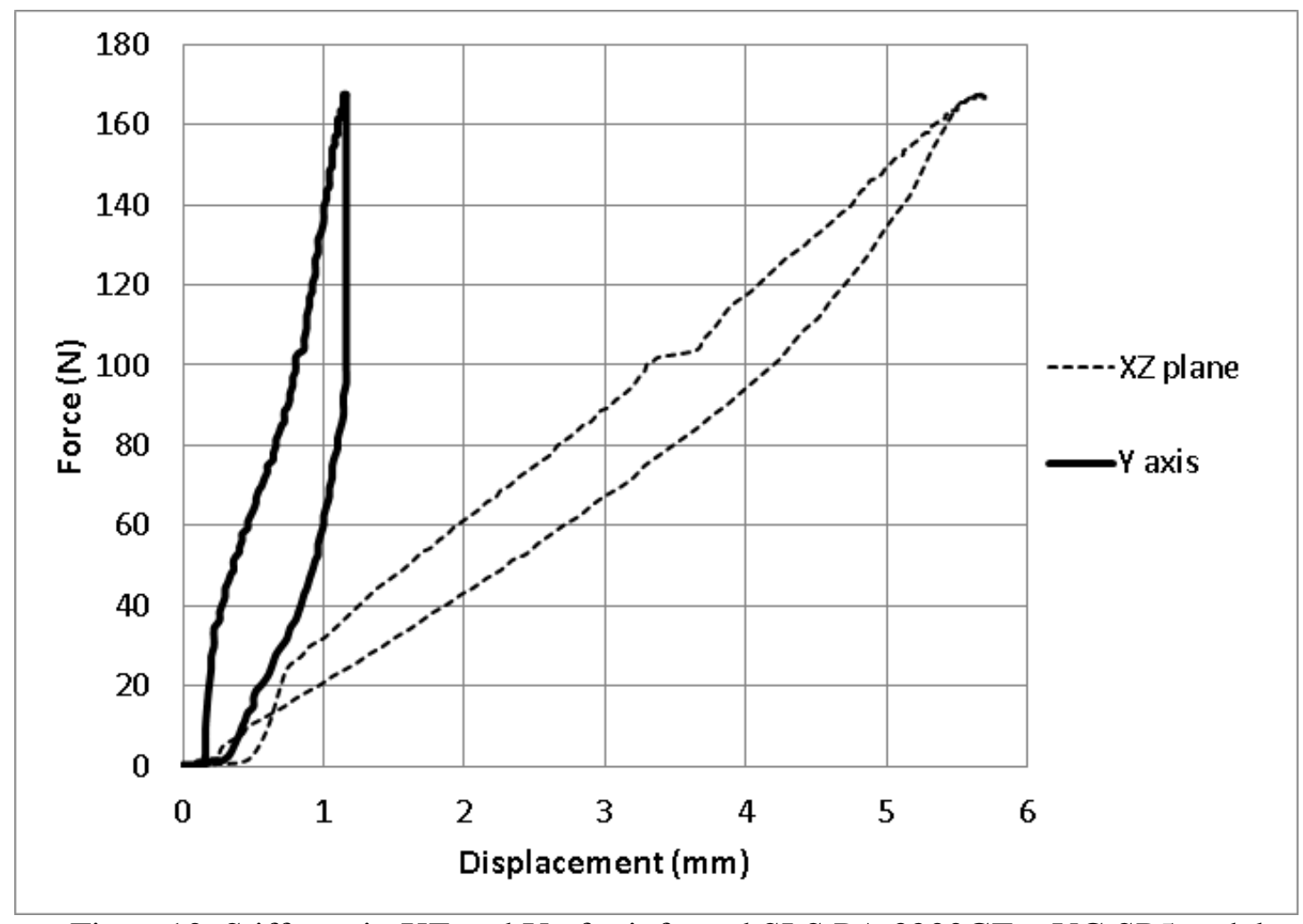

Figure10. Stiffness in XZ and Y of reinforced SLS PA 3200GF + VG SP5 pedal

Figure 11 shows the force applied during the stiffness test $(150 \mathrm{~N})$ and the resultant displacement (XZ and Y components combined) for the tested clutch pedals. The slopes of the reinforced pedal curve and the injected pedal curve were similar, which means similar stiffness. However, the non-reinforced SLS pedal had a lower slope (lower stiffness). On the other hand, it was also observed that both the non-reinforced SLS pedal and the reinforced SLS pedal suffered a strange behavior at the beginning of the test, with an important displacement despite the low value of the load applied. However, this was not appreciated in the injected pedal. In the case of the reinforced or nonreinforced SLS pedals, the steel inserts were glued in the pedals once they were manufactured, while the steel insert in the injected pedal was placed before the injection of the PA66+50\%GF, which means a quite better bonding between them. Hence, the explanation of this behavior is due to a relative displacement between the steel insert and the pedal. 


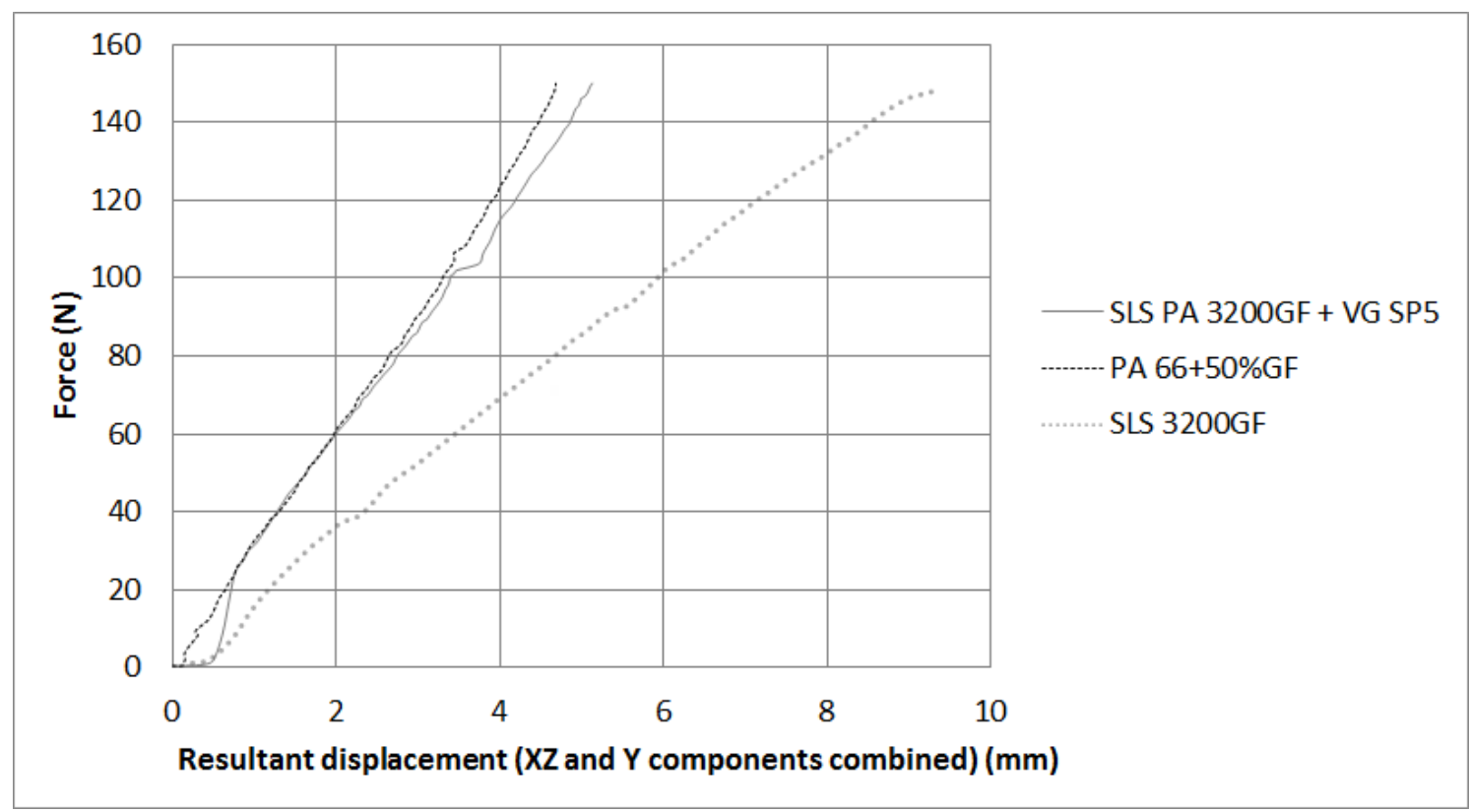

Figure 11. Test of stiffness during loading of clutch pedals

Table 3 summarizes the results and it is clear the significant improvement of the approached reinforced solution related to the SLS part without any reinforcement in terms of stiffness (55\% better). However this reinforced SLS pedal is only $11.7 \%$ worse than the one injected despite the lower mechanical properties of the PA3200 GF and VG SP5 compared to the injected material (PA66+50\%GF).

\begin{tabular}{|l|c|c|c|}
\hline & Displacement $(\mathrm{mm})$ & Stiffness (N/mm) & $\%$ \\
\hline PA 66 50\% GF & 4.68 & 32.05 & 100 \\
\hline SLS 3200 GF & 9.4 & 15.96 & 49.8 \\
\hline SLS 3200 GF +VG SP5 & 5.13 & 28.30 & 88.3 \\
\hline
\end{tabular}

Table 3. Results of testing under a force of $150 \mathrm{~N}$ at room temperature

\section{CONCLUSIONS}

The SLS multi-fiber composite is an alternative and complementary procedure for increasing the mechanical properties of plastic parts made by Selective Laser Sintering. The inclusion of several "fibers" of high resistance polymer, suitable to be processed by vacuum, achieves higher stiffness according to the simulation and test of a clutch pedal of a car, normally manufactured by injection moulding of polyamide and glass fiber. The test of a SLS multi-fiber composite of this clutch pedal showed that the stiffness was increased 55\% related to the only SLS part without any reinforcement and only resulted $11.7 \%$ lower than the injected one. The future inclusion of better epoxy resin, even with glass fiber, could considerably improve the results.

\section{REFERENCES}


Bassoli, E., Gatto, A. and Iuliano, L. (2012), "Joining mechanisms and mechanical properties of PAcomposites obtained by selective laser sintering", Rapid Prototyping Journal, Vol. 18, Iss: 2, pp. 100-108.

Berti, G., D'Angelo, L., Gatto, A. and Iuliano, L. (2010), "Mechanical characterisation of PA-A12O3 compositesobtained by selective laser sintering", Rapid Prototyping Journal, Vol. 16, Iss: 2, pp. 124-129.

Bruggi, M., and Taliercio, A. (2013), "Topology optimization of the fiber-reinforcement retrofitting existing structures", International Journal of Solids and Structures, Vol. 50, Iss: 1, pp. 121-136.

Cevolini, L., Testoni, G. and Davis, S. (2008), "Rapid Manufacturing \& Continued Development of Highly Stressed Fibre-Reinforced Plastic Parts: Motorbike Dash Assembly Made by Windform XT and SLS Technology", paper presented at the 8thAnnual SPE Automotive Composites Conference \& Exhibition (ACCE), September 16th-18th 2008, Michigan, USA, available at: http://speautomotive.com/SPEA_CD/SPEA2008/pdf/e/ET-02.pdf (accessed 6 January 2013).

Esteve F. et al (2012), A guide to successful Rapid Manufacturing, Smithers Rapra, Sha wbury UK

Fiebig, S. and Axmann, J.K. (2013), "Using a binary material model for stress constraints and nonlinearities up to crash in topology optimization", paper presented at the $10^{\text {th }}$ World Congress on Structural and Multidisciplinary Optimization, 19-24 May, Orlando, available at: http://www2.mae.ufl.edu/mdo/Papers/5225.pdf (accessed 10 July 2013)

Gibson, I., Rosen, D.W. and Stucker, B. (2009), Additive Manufacturing Technologies: Rapid Prototyping to Direct Digital Manufacturing, Springer, New York Heidelberg Dordrecht London.

Jain, P.K., Senthilkumaran, K., Pandey, P.M. and Rao, P.V.M. (2006), "Advances in materials for powder based rapid prototyping", paper presented at the International Conference on Recent Advances in Materials and Processing in PSG-tech., Dec. 15-16 2006, Coimbatore, India, available at: http://web.iitd.ac.in/ pmpandey/RP_html_pdf/ADVANCES_IN_MATERIALS_FOR_PO WDER_BASED_RAPID_PROTOTYPING_with_date.pdf (accessed 6 January 2013).

Kumar S. (2003), "Selective laser sintering: A qualitative and objective approach", JOM, Vol. 55, Iss: 10, pp. 43-37

Monzón, M.D., Hernández P.M., Benítez A.N., Marrero M.D., Fernández A. (2009), "Pre dictability of plastic parts behaviour made from Rapid Manufacturing", Journal of Tsin ghua Science and Technology, Vol. 14, pp. 100-107. 
Shi, J., Chen, J., Wang, Y., Li, Z. and Huang, S. (2007), "Study of the selective laser sintering of polycarbonate and postprocess for parts reinforcement", Journal of Materials Design and Applications, Vol. 221, No. 1,pp. 37-42.

Stevinson, B.,Bourell, D.L. and Beaman, J.J. (2008), "Over-infiltration mechanisms in selective laser sintered Si/SiC preforms", Rapid Prototyping Journal, Vol. 14, Iss: 3, pp. 149-154. 